\title{
Comparative Study Between Smooth and Rough Surface of Frictional Force in Mechanics Laboratory at Wolaita Sodo University
}

\author{
Getachew kuma $^{1^{*}} \quad$ Melesse W/Mariam² \\ Wolaita sodo University, College of Natural and Computational Science, Department of Physics, \\ Wolaita ,Ethiopia PO box 138
}

\begin{abstract}
Friction is a resisting force that acts as along the tangent to two surfaces in contact when one body slides over or attempts to slide across another. Friction plays a major role in our daily life. There are different types of friction: static, kinetic, deformation, rolling and the like. But the aim of this project is not to study the type of friction, the project focus on comparative study of frictional force between smooth and rough surfaces and to identify the problems that cause the students' experimental value variation with in the same position of theoretical condition that are discussed in the classroom. For this study, the data were collected by the laboratory experimental values that were recorded by the students in mechanics of frictional forces at W.S.U. This collected data were analyzed in order to compare the experimental value of the smooth surface with the value of the rough surfaces given in the secondary data. Finally, the data is presented to show the causes that hinder the students to find to meet the coherence between the theoretical knowledge and the experimental value
\end{abstract}

Keywords: frictional force, rough, smooth

DOI: $10.7176 /$ APTA/79-02

Publication date:September $30^{\text {th }} 2019$

\section{Introduction}

Comparative studies of a subject under discussion given an insight between the things compared for further insight on the subject matter. Similarly comparing the experimental value on smooth and rough surfaces in mechanics with theoretical value on frictional force in physics gives as the measure of differences or similarities between the two values.

Experiments show that the friction force arises from the nature of the two surfaces. For different surface types, the coefficient of friction varies. There is no simple rule to describe how the coefficient of friction changes with different types of surfaces. Generally speaking the smoother the surface, the weaker the friction. Materials that feel rough would normally have a larger friction. Since there no simple mathematical rules relating frictional forces between different surfaces. (SERWAY-JEWETT $6^{\text {th }}$ Edition ,2004 and (lab manual))

On the basis of this premise, this study attempts to compare the experimental value in mechanics laboratory on frictional force with theoretical value in mechanics a frictional force using the experiments worked out by different groups of students in physics department in Wolaita Sodo University.

Wolaita Sodo University is one of the governmental universities in Ethiopia. The university has a strong orientation to equip the students with basic and higher levels of scientific principles before they graduate. In accordance with this motto, the physics department used to equip the students with theoretical principles and with laboratory experiments. And one of the method in to show the students the relation between the theoretical value and the experimental value worked out in laboratory contexts. And this study focuses on the comparison law. The students used to utilize the knowledge gained at classes a friction with the laboratory experiments. And this helps us to identify the causes that limit the students to demonstrate equally in both sides. Therefore, this study assumes that the condition of the students determine the range of the scores at the experiment against theoretical values discussed in the classes.

\section{Statement of the problem}

This study deals with a comparison of the experimental values of smooth and rough surfaces of frictional force in mechanics laboratory. It attempts to identify the knowledge gap that causes the students to relate effectively in the laboratory as expected by the university. Therefore, the pre-laboratory level of knowledge and the laboratory level experiences differences are the targets of the study. Therefore, the problem of students' not to score the appropriate degree of difference between the theoretical knowledge and experimental practice on the experience gap on the laboratory equipment use and application.

\section{Objective of the study}

3. 3.1 General objectives

-The general objective of the study on to identify the difference between rough and smooth done in frictional 
force in mechanics laboratory of physics department.

\subsubsection{Specific objectives:-}

The specific objective of the study is to understand the causes and effects of the problem that caused the students not to score the result in the laboratory as they learned in the class.

To identify the problems that causes the value or experimental magnitude variation when the experiment done by students with the same mass, the same position/surface contact/, and the same apparatus taken in the lab. Experiment.

\section{Significant of the study}

The result placed a significant emphasize on students and teachers of laboratory technicians. Laboratory teachers motivated to support their students to reduce the problems of the experimental value variations and knowledge gap of the students in the mechanics laboratory of physics department, and the student's egger to exercise and practice their experiment with confidence. [Students report]

\section{The scope of the study}

This study is geographically delaminated that at Wolaita Sodo University in mechanics laboratory of physics department.

\section{Limitations of the study}

The factors limits this study are knowledge gap on the research writing and lack of references that gives information about the study.

\section{Methods Of the Study}

This study will use the following methods:

A) Collection of secondary data. In this case, the laboratory experimental values scored by students in mechanics of frictional forces in W.S.U.

B) Analyzing the data in order to compare the experimental value with theoretical value given in the secondary data.

C) Presenting the findings of comparative study to show the causes that hinder the students to find to meet the coherence between the theoretical value and the experimental value.

\section{Data Analysis}

Table 1 :-the comparison of the students/groups/ experimental value with in contact of smooth surface and the mass of the block. [Students report]

\begin{tabular}{|c|c|c|c|c|c|}
\hline $\begin{array}{l}\text { Surface in } \\
\text { contact }\end{array}$ & $\begin{array}{l}\text { The mass placed } \\
\text { on the block }\end{array}$ & $\begin{array}{l}\text { No of } \\
\text { groups }\end{array}$ & $\begin{array}{l}\text { Total normal } \\
\text { force }\end{array}$ & $\begin{array}{l}\text { Force to keep block moving } \\
\text { uniformly }\end{array}$ & $\begin{array}{l}\text { Force to keep } \\
\text { block moving } \\
\text { uniformly }\end{array}$ \\
\hline \multirow{5}{*}{ Smooth } & \multirow{5}{*}{$276 \mathrm{~g}$ or $0.276 \mathrm{~kg}$} & 1 & $2.76 \mathrm{~N}$ & $2.21 \mathrm{~N}$ & $2.21 \mathrm{~N}$ \\
\hline & & 2 & $2.11 \mathrm{~N}$ & $1.88 \mathrm{~N}$ & $1.88 \mathrm{~N}$ \\
\hline & & 3 & $1.68 \mathrm{~N}$ & $2.11 \mathrm{~N}$ & $2.11 \mathrm{~N}$ \\
\hline & & 4 & $2.76 \mathrm{~N}$ & $2.168 \mathrm{~N}$ & $2.168 \mathrm{~N}$ \\
\hline & & 5 & $2.70756 \mathrm{~N}$ & $1.971 \mathrm{~N}$ & $1.971 \mathrm{~N}$ \\
\hline \multirow{5}{*}{ Smooth } & \multirow{5}{*}{$476 \mathrm{~g}$ or $0.476 \mathrm{Kg}$} & 1 & $4.76 \mathrm{~N}$ & $4.01 \mathrm{~N}$ & $4.01 \mathrm{~N}$ \\
\hline & & 2 & $4.76 \mathrm{~N}$ & $3.41 \mathrm{~N}$ & $3.41 \mathrm{~N}$ \\
\hline & & 3 & $3 \mathrm{~N}$ & $3.8 \mathrm{~N}$ & $3.8 \mathrm{~N}$ \\
\hline & & 4 & $4.6648 \mathrm{~N}$ & $3.541 \mathrm{~N}$ & $3.541 \mathrm{~N}$ \\
\hline & & 5 & $4.66956 \mathrm{~N}$ & $3.34521 \mathrm{~N}$ & $3.34521 \mathrm{~N}$ \\
\hline
\end{tabular}


Table 2: the comparison of the students/groups/ experimental value with in contact of rough surface and the mass of the block. [2]

\begin{tabular}{|c|c|c|c|c|c|}
\hline $\begin{array}{l}\text { Surface in } \\
\text { contact }\end{array}$ & $\begin{array}{l}\text { The mass placed } \\
\text { on the block }\end{array}$ & $\begin{array}{ll}\text { No } & \text { of } \\
\text { groups }\end{array}$ & $\begin{array}{l}\text { Total } \\
\text { normal } \\
\text { force }\end{array}$ & $\begin{array}{l}\text { Force to keep } \\
\text { block moving } \\
\text { uniformly }\end{array}$ & $\begin{array}{l}\text { Force to keep block moving } \\
\text { uniformly }\end{array}$ \\
\hline \multirow{4}{*}{ Rough } & \multirow{4}{*}{$276 \mathrm{~g}$ or $0.276 \mathrm{Kg}$} & 1 & $2.76 \mathrm{~N}$ & $2.11 \mathrm{~N}$ & $2.11 \mathrm{~N}$ \\
\hline & & 2 & $2.688 \mathrm{~N}$ & $2.11 \mathrm{~N}$ & $2.11 \mathrm{~N}$ \\
\hline & & 3 & $2.7048 \mathrm{~N}$ & $2.65 \mathrm{~N}$ & $2.65 \mathrm{~N}$ \\
\hline & & 4 & $2.1658 \mathrm{~N}$ & $\mathrm{I} .8625 \mathrm{~N}$ & $\mathrm{I} .8625 \mathrm{~N}$ \\
\hline \multirow{4}{*}{ Rough } & \multirow{4}{*}{$476 \mathrm{~g}$ or $0.476 \mathrm{Kg}$} & 1 & $4.76 \mathrm{~N}$ & $3.51 \mathrm{~N}$ & $3.51 \mathrm{~N}$ \\
\hline & & 2 & $3.61 \mathrm{~N}$ & $2.984 \mathrm{~N}$ & $2.984 \mathrm{~N}$ \\
\hline & & 3 & $2.64 \mathrm{~N}$ & $3.31 \mathrm{~N}$ & $3.31 \mathrm{~N}$ \\
\hline & & 4 & $3.6358 \mathrm{~N}$ & $3.1267 \mathrm{~N}$ & $3.1267 \mathrm{~N}$ \\
\hline
\end{tabular}

According to tables 1 and 2 the experimental value variations on force to keep block moving uniformly and a little beat on the normal force, whereas the students use the same mass, the same surface, the same apparatus for their experimental practice. [2,3]

Table 3: causes that brought the variations

\begin{tabular}{|l|l|l|}
\hline No & Causes & Effects \\
\hline 1 & $\begin{array}{l}\text { Over load of the laboratory with } \\
\text { very large number of students at } \\
\text { a time. }\end{array}$ & $\begin{array}{l}\text { Noise produced by one group affecting the other group. This has a } \\
\text { negative impact on the score. }\end{array}$ \\
\hline 2 & Students' experience gap & $\begin{array}{l}\text { Brings failure to analyze appropriately } \\
\text { and describe the result. }\end{array}$ \\
\hline 3 & Large size of group members & $\begin{array}{l}\sim \text { Variations in the level of knowledge among the group members. } \\
\sim \text { Reliance in a single member instead of group work. }\end{array}$ \\
\hline 4 & $\begin{array}{l}\text { Problems related to laboratory } \\
\text { equipment's }\end{array}$ & $\begin{array}{l}\sim \text { Producing values which is not expected at the theoretical value. } \\
\sim \text { Time killing done to the oldness of the laboratory equipment. } \\
\sim \text { Lack of modernized experimental materials } \\
\end{array}$ \\
\hline 5 & $\begin{array}{l}\text { In adequate pre-laboratory } \\
\text { knowledge of the frictional force }\end{array}$ & $\begin{array}{l}\text { In adequate laboratory level experimental exercise which leads to } \\
\text { score below the theoretical value. }\end{array}$ \\
\hline
\end{tabular}

\section{Result and discussion}

The finding of this study which categorized into two groups. The first group refers to conditions of the students who are expected to make experiments on frictional forces. They are doing the experience with objective to correlate the theoretical value with experimental value in mechanics laboratory. The proper pre-laboratory knowledge of the students determines the result of the laboratory experiment. In other words students with better understanding of the pre-laboratory knowledge of frictional forces score an appropriate level of score at the laboratory experiences. On the other hand, the students with medium level of pre- laboratory understanding of the concept of frictional forces tend to demonstrate quite magnitude/value/ variations seen or observed from the same experiment done by the students in the laboratory. According to this study the students have got the same or the nearest experimental value of frictional force for the expected theoretical value depends on the mass and the surface in contact.

Again the group members size has a negative bearing on the score of the students in the laboratory experiences. This suggests that the less the group member the greater the score that approximates to the theoretical value. But the more the group member, the less the score due to variations of knowledge gaps and experience limitations.

The second category of the findings relates to the problems of the laboratory equipment's. Knowledge in tested by some standard. In the case the theoretical knowledge in proved by the experimental exercises in the mechanics laboratory of forces. This problem is less compared to the problem relates to the conditions of the students that make to the experiments, 
Therefore an appropriate level of the pre-knowledge of the frictional forces need a compatible level of experience in mechanics laboratory to produce a result that in comenserrate to the theoretical value as discussed in the class.

\section{Recommendation}

$\stackrel{M}{ }$ Making the students being equipped with appropriate level of knowledge because the pre- knowledge of the frictional forces in the class has a great impact on the experimental exercises in the laboratory.

$\stackrel{m}{m}$ Making the laboratory equipment's modern instead of using older tools for the experiment. Because as the tools get older, the experiments done by different groups having with the same mass, the same position of the experiments of frictional forces may show different values.

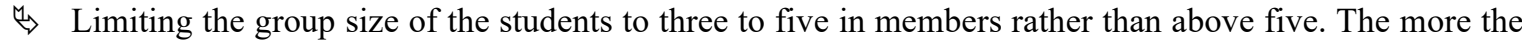
member of the students in the group, the tendency to rely on a single individual may exit.

\section{Conclusion}

Comparative study of experimental value with theoretical value in mechanics laboratory on frictional force in a means to equip students to follow precessions in their works. The theoretical knowledge and the experimental knowledge are the building blocks of mechanics physics that help the students gain the maximum correlation between the two methods.

Therefore, according to the study the students must be equipped in the appropriate level of knowledge of frictional forces before they are sent to corner the experimental value of the frictional forces in the laboratory.

\section{References}

[1] Raymond A. Serway and John W. Jewett, J. (2014, 2010, 2008 by Raymond A. Serway). Physics for Scientists and Engineers with modern physics. University of California at Los Angeles: Physical Sciences: Mary Finch and Physics and Astronomy:.

[2] Lab. Experiment report modules of frictional force written by different students in mechanics laboratory of physics department in W.S.U at 2019.(students report)

[3] Factors affecting frictional force, level: secondary 4 (lab manual) 